\title{
PERILAKU WANITA TERHADAP KEKERASAN DALAM NOVEL ALUN SAMUDRA RASA KAJIAN FEMINIS PSIKOANALISIS JULIET MITCHELL
}

\author{
WOMEN'S BEHAVIOR OF VIOLENCE IN ALUN SAMUDRA NOVEL \\ FEMINIST STUDY OF PSYCHOANALYSIS JULIET MITCHELL
}

\author{
Tya Resta Fitriana
}

Fakultas Keguruan dan Ilmu Pendidikan, Universitas Sebelas Maret Surakarta Jalan Ir. Sutami No 36 A, Kentingan, Surakarta, Indonesia

tyarestafitriana@gmail.com

(Naskah diterima tangga 31 Juli 2019, direvisi terakhir tanggal 29 September 2021, dan disetujui tanggal 19 Oktober 2021)

DOI: https:/ / doi.org/10.26499/wdprw.v49i2.370

\begin{abstract}
The purpose of this study was to analyze the behavior of women against violence within novel Alun Samudra Rasa using feminist psychoanalysis study. This study used descriptive qualitative method. This method is used to describe the facts discovered furthermore these facts were analyzed using feminist perspective psychoanalysis Juliet Mitchell. This research results in two things: 1) behavior of women when getting violence and 2) things that cause women to exhibit such a behavior. There are seven types of women's behavior when they experience violence, namely expulsion, rejection, accusation, divorce, physical violence, psychological violence and loving men other than their husbands The appearance of these behaviors is caused by mindset factors that have to do with unconsciousness and kinship system factors. Factors kinship system in the study, are related to parenting. Different parenting will affect the difference in mindset and behavior.
\end{abstract}

Keywords: women's behavior; feminist psychoanalysis Juliet Mitchell; violence

\begin{abstract}
Abstrak
Tujuan penelitian ini adalah untuk menganalisis perilaku wanita terhadap kekerasan di dalam novel Alun Samudra Rasa menggunakan kajian feminis psikoanalisis. Penelitian ini menggunakan metode deskriptif kualitatif. Metode ini digunakan untuk memaparkan fakta-fakta yang ditemukan selanjutnya fakta tersebut dianalisis dengan menggunakan perspektif feminis psikoanalisis Juliet Mitchell. Penelitian ini menghasilkan dua hal, yaitu 1) wujud perilaku wanita ketika mendapatkan kekerasan dan 2) hal yang menyebabkan wanita memperlihatkan sikap tersebut. Sikap wanita ketika mengalami kekerasan ada lima jenis yaitu pengusiran, perceraian, kekerasan fisik, kekerasan psikologis, dan mencintai laki-laki lain selain suaminya. Munculnya perilaku tersebut disebabkan oleh faktor pola pikir yang ada hubungannya dengan faktor ketidaksadaran dan faktor kinship system. Faktor kinship system di dalam penelitian, berhubungan dengan pola asuh. Pola asuh yang berbeda akan berpengaruh terhadap perbedaan pola pikir dan perilaku seseorang.
\end{abstract}

Kata-kata kunci: sikap wanita; feminis psikoanalisis Juliet Mitchell; kekerasan 


\section{Pendahuluan}

Novel Alun Samudra Rasa adalah novel berbahasa Jawa yang isinya mengenai permasalahan wanita khususnya wanita Jawa. Tokoh wanita di dalam novel Alun Samudra Rasa digambarkan sebagai sosok yang sering menerima perlakuan kasar suaminya. Aspek ketertindasan perempuan dalam karya sastra tidak hanya dipaparkan dalam karya dalam bentuk novel, karya dalam bentuk sastra lisan pun ada yang menggambarkan aspek ketertindasan ini. Penelitian dari Vidiyanti (2014) menggambarkan adanya ketertindasan perempuan dalam sastra lisan kentrung. Penggambaran tersebut merupakan refleksi dari keadaan wanita di masyarakat yang terefleksi dalam karya sastra.

Novel ini menceritakan kehidupan tokoh Intan yang menerima berbagai macam kekerasan di dalam rumah tangga. Kekeras-an tersebut berpengaruh terhadap kondisi psikologisnya sehingga menimbulkan rasa kecemasan. Perasaan cemas yang dirasakan Intan berpengaruh terhadap perilakunya. Perilaku tersebut merupakan representasi dari rasa cemas serta bagian dari cara yang digunakan Intan untuk mengurangi atau menghindari rasa cemas tersebut. Tong (dalam Wiyatmi, 2012: 18) menjelaskan bahwa perilaku yang diperlihatkan oleh seseorang ada hubungannya dengan kondisi psikologis, khususnya berhubungan dengan pola pikir wanita.

Mitchell (2000: 25) menjelaskan bahwa perkembangan pola pikir dipengaruhi oleh faktor ketidaksadaran dan kinship sysytem atau hubungan persaudaraan Pendapat Mitchell sesuai dengan fokus permasalahan di dalam penelitian ini teori yang dikemukakan oleh Mitchell digunakan untuk memaparkan perilaku wanita sebagai ekspresi psikologisnya jika dihubungkan dengan masalah kekerasan yang dialaminya. Masalah ini menarik untuk dikaji, karena belum banyak peneliti yang yang mengkaji aspek kinship system dan faktor ketidaksadaran dalam hubungannya dengan kondisi psikologis wanita yang digambarkan dalam karya sastra Jawa. Penelitian ini akan memaparkan perilaku wanita terhadap praktik kekerasan di dalam rumah tangga dan faktor yang memengaruhi keadaan psikologis wanita.

Berdasarkan landasan penelitian di atas, tujuan dari penelitian ini adalah untuk memaparkan perilaku wanita terhadap praktik kekerasan dan faktor yang menyebabkan munculnya perilaku tersebut. Penelitian ini diharapkan memberikan sumbangsih terhadap perkembangan ilmu sastra dan dapat dijadikan sebagai bahan ajar di perkuliahan khususnya kajian feminis psikoanalisis.

Endraswara (2011: 146) memaparkan bahwa analisis kritik sastra feminis adalah kritik sastra yang fokus kajiannya terhadap peran dan kedudukan wanita. Kritik sastra feminis berupaya untuk menjelaskan ketimpangan gender yang terefleksi dalam karya sastra. Sedangkan Ogene memaparkan seperti dibawah ini.

The idea of psycho-analysis revolves round the concept that peoplesee actions are determined by their pre-stored ideas of the recurrent events. Although forgotten memories and experiences are believed to be packed in a "library" of dark sides of the mind, these surface later in dreams, actions, gestures and expressions (Ogene and Mbanefo, 2013).

Ide dari psikoanalisis bahwa hubungan perilaku seseorang itu dipengaruhi oleh alam bawah sadar berupa perilaku, gerak tubuh dan ekspresi.

Wiyatmi (2012: 19) menjelaskan bahwa kritik sastra feminis psikoanalisis merupakan kritik terhadap pendapat Sigmud Freud masalah penis envy. Mitchell (dalam Duschinsky, Robby \& Susan Walker, 2015: 58) memaparkan bahwa perbedaan peran dan kedudukan antara wanita dan laki-laki dipengaruhi oleh masyarakat. Mitchell (2000: 6-8) menjelaskan 
bahwa dalam perkembang-an kepribadian seseorang melalui dua proses yaitu primary process dan secondary process. Insting, naluri, hasrat-hasrat dan aturan-aturan akan ditemukan dalam primary process, sedangkan secondary process mengha-silkan suatu keputusan yang berupa pola pikir atau tingkah laku. Pola pikir yang dihasilkan merupakan dasar dari pembentukan ideologi seseorang. Wiyatmi (2013: 19) memaparkan bahwa kritik sastra feminis psikoanalisis memfokuskan kajian pada tulisantulisan perempuan karena para feminis percaya bahwa pembaca perempuan biasanya mengidentifikasikan dirinya dengan menempatkan dirinya pada tokoh perempuan, sedangkan tokoh perempuan tersebut pada umumnya merupakan cerminan penciptanya.

\section{Metode}

Metode yang digunakan dalam penelitian ini adalah metode penelitian deskriptif kualitatif. Ratna (2015: 53) menjelaskan bahwa metode penelitian deskriptif digunakan dengan memaparkan fakta-fakta yang ditemukan selanjutnya fakta tersebut dianalisis. Penelitian ini fokus terhadap masalah psikologis tokoh wanita di dalam cerita. Permasalahan-permasalahan tokoh wanita di dalam novel dikaji dengan menggunakan pendekatan feminis psikoanalisis.

Penelitian ini menggunakan metode membaca dengan reading as women oleh Jonathan Culler untuk memudahkan analisis (Wiyatmi, 2012). Teknik membaca dengan reading as woman yaitu memfokuskan permasalahan di dalam novel Alun Samudra dari sudut pandang wanita. Metode ini digunakan untuk memaparkan sikap wanita ketika mendapatkan kekerasan oleh suaminya dan faktor yang memengaruhi munculnya perilaku tersebut. Berikut data yang digunakan dalam penelitian ini.
Tabel 1

Wujud Perilaku Wanita terhadap Kekerasan dan Faktor yang Memengaruhi

\begin{tabular}{lll}
\hline No. & $\begin{array}{c}\text { Perilaku Wanita terha- } \\
\text { dap Kekerasan }\end{array}$ & $\begin{array}{c}\text { Faktor yang } \\
\text { Memengaruhi }\end{array}$ \\
\hline 1. & Mengusir & Pola asuh \\
2. & Menggugat cerai suami & \\
3. & Kekerasan fisik & \\
\hline 4. & Kekerasan psikologi & Faktor ketidak- \\
5. & Mencintai laki-laki lain & sadaran \\
& kecuali suaminya & \\
\hline
\end{tabular}

Wiyatmi (2012: 18) menjelaskan bahwa kritik sastra feminis psikoanalisis mengkaji perilaku wanita yang mendapatkan kekerasan. Di dalam kajianfeminis psikoanalisis, perilaku yang ditunjukkan oleh wanita dihubungkan dengan keadaan psikologisnya. Penelitian ini akan menggunakan model kritik sastra feminis psikoanalisis Juliet Mitchell. Konsep dari Mitchell yang digunakan dalam penelitian ini adalah perkembangan kepribadian yang dipengaruhi oleh faktor ketidaksadaran atau alam bawah sadar dan kinship system atau hubungan persaudaraan yaitu konsep yang mengemukakan bahwa keluarga adalah sistem dasar yang membangun karakter dan pola pikir seseorang khususnya masalah sexualdifference.

Sumber data penelitian ini adalah novel berbahasa Jawa yang berjudul Alun Smaudra Rasa. Teknik mengumpulkan data di dalam penelitian ini dengan cara membaca dan menulis. Teknik membaca membutuhkan ketelitian dan kecermatan peneliti untuk membaca sumber data yang berhubungan dengan tujuan penelitian. Di dalam penelitian ini, teknik membaca yang digunakan adalah reading as women.

Teknik analisis data yang digunakan di dalam penelitian ini adalah analisis konten dengan unit analisis berupa kata, frasa, kalimat, klausa dan wacana yang menggambar- 
kan masalah inferioritas wanita. Tahapan analisis data yang digunakan dalam penelitian ini adalah 1) reduksi data, 2) klasifikasi data, 3) display data, dan 4) penafsiran atau interpretasi (Siswantoro, 2005: 25 ).

\section{Hasil Penelitian dan Pembahasan}

Opresi merupakan tindakan pemaksaan atau merampas kehendak seseorang untuk melakukan sesuatu dengan kekuatan yang dimilikinya, sehingga dapat membuat seseorang yang berada di bawah opresi merasakan kesengsaraan dan penderitaan. Psikoanalisis akan digunakan untuk mengkaji perilaku wanita ketika mendapatkan kekerasan dari suaminya. Praktik kekerasan tersebut disebabkan oleh pola pikir yang salah tentang sexual difference sehingga sering menempatkan wanita pada posisi yang inferior. Wujud perilaku wanita ketika menghadapi kekerasan dan faktor yang memengaruhi seperti di terurai dalam tabel 1.

Di dalam penelitian ini akan dibahas dua permasalah yaitu perilaku wanita terhadap praktik kekerasan di dalam rumah tangga dan faktor yang memengaruhi. tersebut..

\section{Sikap Wanita terhadap Kekerasan}

Tokoh Intan menunjukkan sikap yang sifatnya menentang terhadap praktik kekerasan. Intan menunjukkan perilaku mengusir, menceraikan suaminya, kekerasan fisik, kekerasan psikologis dan mencintai laki-laki lain kecuali suaminya, seperti pembahasan di bawah ini.

\section{Mengusir}

Bregas memiliki rasa cemburu yang berlebihan terhadap Intan. Hubungan antara Intan dan Mr. Tanaka juga dijadikan Bregas sebagai alasan untuk menuduh Intan telah berbuat selingkuh. Padahal, hubungan antara Intan dan Mr. Tanaka hanya sebatas hubungan profesional kerja. Masalah ini menjadi faktor penyebab pertengkaran di antara mereka.
"Yen panjenengan pancen yakin aku wis tumindak sedheng. Geneya aku ora kok pegat wae utawa mbok balekake marang wong tuwaku?" kandhane kanthi ngempet lara.

“Dadi kowe ngakoni?" Bregas bali mojokake sing wadon.

"Yen iya panjenengan arep apa?" kandhane Intan gregeten

“Dhasar lonthe! Plak ...!" Tangane Bregas mampir ing pipine Intan.

"Tulung, panjengan metu saka kamar iki, utawa aku sing metu," kandhane nahan emosi. Isin yen anggone regejekan kuwi nganti dirungu dening Mona sing lagi ngancani Sekar ing kamar sebelah (Pangastuti, 2016: 22-23).

Terjemahan: Jika kamu yakin jika aku selingkuh. Kenapa kamu tidak ceraikan aku saja atau kamu kembalikan saja aku kepada orang tuaku?" katanya sambil menahan rasa sakit hati.

"Jadi kamu mengakui?" Bregas kembali menjudutkan istrinya.

"Jika iya kamu mau apa?" Jawab Intan

"Dasar pelacur! Plak." tangan Bregas menampar pipi Intan.

“Tolong Mas Bregas keluar dari kamar ini atau aku yang keluar" jawan Intan penuh emosi. Malu jika pertengkaran ini sampai terdengar oleh Mona yang sedang menemani Sekar di kamar sebelah.

Dari petikan novel di atas menggambarkan bahwa pengusiran yang dilakukan oleh Intan sebagai bagian dari cara untuk menghindari perselisihan yang lebih besar. Struktur kepribadian superego memberikan pengaruh pada ego agar berperilaku sesuai dengan norma-norma dan etika masyarakat Jawa. Etika masyarakat Jawa sangat berhubungan dengan prinsip rukun. Rukun adalah dasar keseimbangan emosi seseorang, sehingga orang yang berusaha menjaga 
keseimbangan ini tidak akan mengalami konflik.

Kata isin juga bisa menjelaskan dimensi psikologis orang Jawa. Geertz (dalam Suseno, 1985: 64) memaparkan bahwa rasa isin atau malu menjadi tanda bahwa seseorang telah memiliki kepribadian yang matang. Dimensi psikologis orang Jawa adalah rasa malu dan sungkan. Dimensi tersebut digunakan agar ego bisa bertindak laras dengan norma-norma masyarakat.

Kultur budaya Jawa sebenarnya menempatkan perempuan dalam posisi yang unggul. Berdasarkan penelitian yang dilakukan oleh Irianingsih (2016) terhadap dua naskah Jawa yaitu Serat Wulang Estri dan Serat Wulang Putri, kebudayaan Jawa menempatkan wanita pada posisi yang baik. Disebutkan dalam penelitiannya bahwa wanita yang dapat dikategorikan memiliki tempat yang baik adalah perempuan yang memiliki watak dan sikap njawani yang tecermin dalam pembawaannya. Jadi tidak mungkin perempuan yang asal-asalan dalam hidup akan mendapatkan tempat yang baik. Seperti peribahasa Jawa "sapa nandur bakal ngundhuh" yang artinya siapa yang menanam akan menuai apa yang diperbuat (Sumodiningrat dan Ari Wulandari, 2014). Penjelasan inilah yang menjadi dasar bahwa segala sikap yang dapat memicu konflik terbuka dengan orang lain menjadi tanda bahwa perempuan tersbeut belum matang secara psikologis sehingga kebanyakan, perempuan Jawa cenderung mengalah dan diam jika diperlakukan kasar dan tidak adil oleh pasangannya. Sikap yang ditunjukkan oleh Intan adalah sebuah perjuangan untuk menghindari konflik yang lebih besar dengan suaminya.

\section{Menggugat Suaminya}

Masalah perceraian di dalam lingkungan masyarakat Jawa adalah hal yang tabu dan sebisa mungkin dihindarkan. Namun, perkem- bangan zaman telah membawa pengaruh terhadap pola pikir masyarakatnya. Intan sebagai penggambaran tokoh wanita Jawa juga menunjukkan perkembangan pola pikir yang dipengaruhi oleh perkembangan zaman.

Masalah kekerasan yang sering diterimanya menimbulkan pengaruh pada kondisi psikologisnya yaitu berupa kecemasan.

"Yen njenengan pancen wis ora percaya maneh marang aku, becike perkawinan iki kita pungkasi wae. Aku wis kesel pendhakpendhak ketemu mesthi ribut. Aku kesel tansah mbok cubriyani terus kaya iki," kandhane sawise nelesi gorokane nganggo wedang putih.

"kowe pantes dicubriyani!" kandhane Bregas atos.

“Tinimbang saben-saben tansah cubriya kaya iku, mula prayogane awake dhewe pisah wae."

"Aku ngerti, kowe selak gatel kepengin bisa sesandhingan karo dhemenanmu. Mula adreng olehmu njaluk pisah. Nanging aku ora bakal ngeculake kowe!" (Pangastuti, 2016: 124).

Terjemahan: " Jika kamu sudah tidak percaya lagi kepada aku, baiknya pernikahan kita sudahi sampai disini. Aku capek setiap kali kita bertemu selalu ribut. Aku juga capek selalu kamu curigai" katanya setelah meminum segelas air.

"kamu memang pantas dicurigai" jawab Bregas.

"Daripada selalu dicurigai seperti itu, sebaiknya memang kita lebih baik berpisah"

"Aku tahu kamu ingin segera bersanding dengan pacarmu itu. Sehingga kamu bersikeras untuk minta berpisah. Tapi aku tidak akan melepaskanmu!"

Kecemasan yang timbul pada diri Intan disebabkan oleh perselisihan yang sering terjadi di antara Bregas dan Intan. Intan sudah berupaya supaya perceraian tersebut tidak terjadi. Masih ada niat dari Intan untuk 
mempertahankan rumah tangganya asalkan Bregas bisa merubah sikapnya. Namun Bregas tidak menunjukkan perubahan sikap tersebut dan perceraian menjadi jalan terakhir yang ditempuh.

Ketegasan yang ditunjukkan oleh Intan tidak lepas dari pengaruh model dari sikap dan perilaku orang tuanya. Mitchell berpendapat seperti di bawah ini.

Mankind never lives entirely in the present.

The past, the tradition of the race and the people, lives on in the ideologies of the superego and yields only slowly to the influences of the present and to new change (Duschinsky \& Susan Walker, 2015: 60).

Manusia tidak bisa lepas dari pengaruh pengalaman-pengalaman di masa lalu yang nantinya akan memengaruhi pandangan hidup seseorang. Sikap orang tua Intan yang menolak kekerasan terhadap wanita ikut berperan dalam perkembangan pola pikir Intan.

Perilaku yang ditunjukkan Intan merupakan ekspresi psikologisnya. Jadi masalah perceraian yang dimaksudkan hanya sebatas representasi keadaan psikologis Intan jika dilihat dari sudut pandang psikologis. Hal ini sejalan dengan pandangan Tong (2006) bahwa feminis psikoanalisis dan gender melihat cara bertindak perempuan berakar pada psikis perempuan, terutama dalam cara berpikir perempuan. Sebagai makhluk individual, perempuan juga mempunyai keinginan untuk diperhatikan, dihargai, dan diakui statusnya dalam rumah tangga. Perasaan tidak diakui dan dihargai inilah yang akhirnya menyurutkan perjuangannya mempertahankan rumah tangganya dengan Bregas, suaminya. Intan memilih untuk mengusir suaminya dari rumahnya.

\section{Kekerasan Fisik}

Kekerasan fisik merupakan wujud kekerasa domestik (Sugihastuti \& Itna Hadi Saptiawan, 2010: 7). Kekerasan fisik yang dimaksudkan dalam kajian ini adalah wujud respon tokoh wanita ketika mengalami kekerasan.
"Nalika ing Yogyakarta kowe mblayang menyang ngendi wae? Karo sapa? Karo bosmu sing ana kene apa karo lanangan liya? Ngakuwa wae! Yen kowe gelem ngaku mungkin aku bisa aweh pangapura."
Plak!
Tangan kiwane Intan sing bebas langsung mampir ing pipine Bregas.
"Yen njenengan wis ora percaya maneh marang aku, geneya aku ora kok balekake marang wong tuwaku wae?" Intan mbales pamandenge sing lanang (Pangastuti, 2016: 15).
Terjemahan:
“Ketika di Yogyakarta kamu kelayapan ke- mana saja? Sama siapa? Dengan bosmu atau dengan lelaki lain? Jujur saja! Jika kamu mau jujur mungkin aku akan memberimu maaf.: Plak!
Tangan kiri Intan langsung menampar pipi Bregas.
"Jika kamu sudah tidak percaya lagi denganku, kenapa tidak kamu kembalikan aku kepada orang tuaku saja?" Intan membalas menatap tajam suaminya.

Intan dituduh telah berbuat selingkuh secara reflek menampar Bregas. Perilaku Intan merupakan wujud dari nalurinya. Freud (dalam Minderop, 2011: 26--27) membagi naluri menjadi dua yaitu naluri hidup dan naluri mati. Naluri mati menyebabkan seseorang bersikap dan berperilaku agresif dan destruktif. Perilaku Intan yang kasar adalah penggambaran naluri Intan untuk melindungi dirinya

Naluri terletak di alam bawah sadar dan memiliki sifat agresif. Walaupun memiki sifat agresif superego atau unsur kepribadian yang berhubungan dengan moral berpengaruh kuat di dalam dirinya, perilaku Intan masih bisa dikontrol. Superego sebagai kontrol dari diri manusia agar ego 
merepresentasikan perilaku dan sikap yang sesuai dengan norma-norma masyarakat. dorongan naluri tersebut yang memunculkan perilaku berupa kekerasan fisik kepada tokoh laki-laki.

Perilaku yang ditunjukkan oleh Intan merupakan pengaruh dari perkembangan zaman yang menyebabkan perubahan pola pikir wanita. Pengaruh negatif dari patriarki yang menyebabkan munculnya sifat arogansi laki-laki sering memosisikan wanita sebagai pihak yang marginal. Sejatinya patriarki adalah sistem keluarga yang dianut oleh mayoritas masyarakat Jawa bisa diterima asalkan tidak menimbulkan ketimpangan peran antara wanita dan laki-laki.

\section{Kekerasan Psikologis}

Kekerasn psikologis termasuk kekerasan nonseksual, kekerasan emotional yang berhubungan dengan kondisi psikologis wanita (Sugihastuti, 2010: 171). Kekerasan psikologis yang dilakukan oleh Intan diwujudkan dalam bentuk sikap dan kata yang kasar .

Omah sepi nalika Bregas bali saka anggone lelungan menyang luar kota sajroning telung dina iki. Rencanane sing wis tharik-tharik dadi buyar maneh nalika nemu dluwang sasuwek sing diselehake ing meja cedhak tempat tidur kanthi ditindhihi jepitan dhasi.

"Aku bali Yogya". Mung kuwi unine tulisan sing ana ing dluwang kasebut. Cekak aos. Ora ana keterangan liyane maneh. Raine Bregas sanalika langsung abang. Tangane nggegem. Kertas diremet karo untune digeget rapet (Pangastuti, 2016: 78).

Terjemahan:

Rumah nampak sepi ketika Bregas kembali dari luar kota setelah 3 hari. Rencana yang sudah disusun ternyata bubar ketika membaca secarik kertas yang terletak di meja dekat tempat tidur di bawah penjepit dasi.

"Aku pulang Jogja". Hanya ini yang tertulis pada secarik kertas tersebut. SIngkat. Tidak ada keterangan lain. Seketika muka Bregas memerah. Kertas digenggam kuat olehnya.
Perilaku Intan yang digambarkan dalam petikan novel menimbulkan rasa kecewa Bregas. Bregas merasa tidak dihargai lagi sebagai seorang suami. Tetapi sebenarnya, kepulangan Intan ke Yogyakarta adalah bagian dari usaha Intan untuk menenangkan pikirannya. Perilaku Intan tersebut adalah mekanisme pertahanan ego yaitu disosiasi. Disosiasia dalah menghindari segala hal yang bisa menyebabkan kecemasan.

Bregas yang mengetahui kepergian Intan ke Yogyakarta merasa cemas jika Intan selingkuh dan akhirnya meninggalkan Bregas. Padahal biasanya yang memiliki sifat bergantung adalah istri atau wanita.

\section{Mencintai Laki-laki selain Suaminya}

Kekerasan yang dialami Intan dan perselisihan di dalam rumah tangganya membuat Intan berpikir bahwa tidak ada sosok yang sebaik Pram, mantan pacar Intan. Pram adalah sosok yang dianggap paling ideal. Perasaan cinta yang sudah lama dipupus akhirnya muncul kembali. Walaupun di hati Intan masih tersimpan cinta untuk Pram, tetapi Intan berusaha agar perilakunya tidak menyimpang dari norma masyarakat.

Hubungan Intan dan Pram yang sempat berjarak, akhirnya dipertemukan lagi secara tidak sengaja di Yogyakarta. Pertemuan di antara keduanya semakin sering ketika Intan membuka bisnis baru di bidang art shop. Intan yang masih belum mengerti dunia art shop membutuhkan bantuan dari Pram. Intensitas waktu bersama membuat hubungan yang sempat dingin kembali mencair. Namun, Intan masih berusaha menjaga batasan-batasan yang ada. Hal ini bisa dilihat di dalam petikan novel di bawah ini.

\footnotetext{
"Rungokna swarane atimu. Swara atimu sing paling jero. Swara ati kuwi mujudake cahaya surgawi kang dikirim Gusti kanggo nuntun jangkahmu. Dadi rungokna apa sing
} 
dikandhakake dening atimu," Pram mbales panyawange Intan. Mripat kekarone tempuk. Embuh sapa sing miwiti, wong loro bali gapyuk rerangkulan.

"Aja ngendika apa-apa maneh. Aku kepengin menikmati rasa iki sedhela wae. Mumpung kita isih ana kene." Intan nyendhekake sirahe ing dhadhane Pram, ngrungokake keteg jantunge priya iku. Dhigdhug, dhig-dhug .... dinikmati swara kuwi. Tangane sing pengkuh kaya-kaya ngandhut strom puluhan volt, sing kanthi alon rumambat ing saranduning angga, banjur katut iline getih mlebu jroning nala. Nuwuhake rasa anget, rasa tentrem ... tentrem kang endah!

Nganti sauntara wong loro anggone meneng lan anteng kaya iku. Kekarone padha dene keli jroning ulegan rasa sing ngundhakundhak dhadha. Rasa sing angel dipahami lan amung bisa dinikmato, dilaras lan diayati. (Pangastuti, 2016: 308).

Terjemahan:

Dengarkan suara hatimu. Suara terdalam hatimu. Suara hati merupakan cahaya surga yang dikirim oleh Tuhan untuk menuntun langkahmu. Jadi dengarkan apa kata hatimu." Pram memandang Intan. Mata keduanya beradu. Entah siapa yang memulai, keduanya kembali berpelukan.

“Jangan berkata apa-apa lagi. Aku hanya ingin menikmati rasa ini sebentar saja. Mumpung kita masih disini." Intan menyandarkan kepalanya di dada Pram, sambil mendengarkan degup jantungnya. Dhigdhug-, dhig-dhug... dinikmati suara itu. Tangannya yang kuat seperti memiliki aliran listrik puluhan volt, secara perlahan merambat disekujur tubuhnya, terbawa aliran darah kemudian masuk kedalam hati. Menimbulkan rasa hangat, rasa tentram... tentram yang indah!

Sampai beberapa waktu keduanya diam. Keduanya terhanyut dalam rasa yang bergejolak dalam dada. Rasa yang sulit dimengerti, hanya bisa dinikmati, dirasakan dan dihayati.
Gejolak jiwa yang dirasakan oleh Intan karena terpaan masalah dalam hidupnya membuat kondisi psikologisnya terganggu. Sosok Pram adalah orang yang bisa menenangkan dan menuntun Intan. Keduanya tidak bisa mengendalikan perasaan masing-masing, hingga pada akhirnya mereka saling berpelukan.

Rasa cinta yang masih hidup di dalam hati Intan, dikendalikan supaya tidak merusak tatanan. Walaupun ketika itu mereka memiliki kesempatan yang lebar untuk berbuat lebih, tetapi nalar dan iman masih menunjukkan jalan yang benar. Penggambaran tersebut adalah wujud dari superego yang memberi arahan kepada manusia untuk berperilaku sesuai dengan norma dan aturan masyarakat.

Dominasi adalah penguasaan oleh pihak yang lebih kuat terhadap pihak yang lebih lemah. Dominansi struktur superego yang dominan di dalam diri seseorang berasal dari didikan orang tua. Nilai-nilai agama dan moral yang seringkali disampaikan dalam bentuk larangan, perintah, dan nasihat adalah bagian dari unsur ketidaksadaran yang memengaruhi kepribadian seseorang. Nilai-nilai yang tertanam tersebut digunakan sebagai penentu seseorang untuk mengambil keputusan di masa depan.

\section{Faktor yang Memengaruhi}

Setiap perilaku yang ditunjukkan wanita merupakan ekspresi psikologisnya. Mitchell (2000) memaparkan bahwa perkembangan kepribadian seseorang itu dipengaruhi oleh proses-proses ketidaksadaran dan berhubungan juga dengan kinship network. Kedua aspek tersebut akan membentuk pola pikir seseorang yang pada akhirnya pola pikir tersebut akan memengaruhi perkembangan kepribadian seseorang. 


\section{Pola Asuh/Kinship Network}

Pola asuh yang diterapkan keluarga Intan adalah pola asuh yang bersifat demokratis. Pola asuh ini menjadikan Intan dapat hidup lebih mandiri dan memiliki tanggung jawab yang besar atas semua pilihan hidupnya.

Intan pancen digedhekake jroning kulawarga priyayi sing santun. Wong tuwane klebu kinormat sing dieringi dening masyarakat sakiwatengene. Najan anak ontang-anting nanging ora ungunan. Kuwi amarga dhidhikan bapake sing dhisiplin lan panggulawenthah saka ibune sing kebak asih lan wicaksana. Kawit Intan isih cilik wis ditemenake rasa tepa selira ing jiwane. Pancen, ibune ora tau ngandhani kanthi langsung, nanging biasane lewat dongeng, liwat buku-buku apa dene tuladha saka ibune dhewe. Kepriye sikape ibune marang rewang ing ngomahe, marang tangga teparo lan uga marang sedulur-sedulure saka garis ibu apa dene bapak. Kabeh kuwi kerekam cetha ing engatene. Ah, mangsa-mangsa kang endah! Pengin rasane bisa bali dadi bocah maneh. Urip tanpa sanggan, batine Intan kelingan mangsa-mangsa endah sing saiki wis mungkur kuwi (Pangastuti, 2016: 25).

Terjemahan:

Intan dibesarkan dalam keluarga yang santun. Orang tuanya termasuk orang terhormat dan disegani oleh masyarakat. Walaupun anak tunggal tetapi dia tidak manja. Hal ini karena didikan dari ayahnya yang disiplin dan ibunya yang bijaksana serta penuh kasih. Dari kecil Intan sudah ditanamkan rasa empati dalam dirinya. Memang, ibunya tidak memberitahu hal ini secara langsung tetapi biasanya dengan cara mendongeng, buku atau tindakan ibunya yang bisa dilihat secara langsung oleh Intan. Bagimana sikap ibunya kepada pembantu dirumah, sikap ibunya kepada tetangga dan saudara. Semua terekam dalam ingatan Intan." Ah, masamasa yang indah! Ingin rasanya kembali ke masa kecil. Hidup tanpa beban". Batin Intan mengingat masa-masa yang lalu.
Dari petikan novel di atas diketahui bahwa pola didik yang diterapkan oleh orang tua Intan membawa pengaruh terha-dap kepribadian Intan. Masalah moral juga menjadi konsen Pak Surtana dan Ibu dalam mendidik Intan. Nilai-nilai moral tersebut ditanamkan lewat perilaku langsung dan tidak langsung. Perilaku langsung tersebut ditunjukkan lewat sikap orang tua Intan terhadap asisten rumah tangganya, tetangga dan kepada orang-orang disekeliling Pak Surtana. Setiap perilaku tersebut direkam oleh Intan dan pada akhirnya tertanam di dalam diri Intan. Penanaman nilai moral juga bisa dilakukan melalui media dongeng. Media dongeng menjadi salah satu alternatif menanamkan nilai-nilai kebaikan tanpa disadari anak.

Masalah kinship system berhubungan dengan hubungan struktural di dalam keluarga. Mitchell (2000) memaparkan bahwa it is not the family but the structural relationship between families that constitutes the elementary form of human. Hubungan struktural di dalam keluarga nantinya akan berpengaruh terhadap pemaknaan peran dan kedudukan antara wanita dan pria dalam masyarakat. Pak Surtana tidak pernah menempatkan istrinya sebagai kanca wingking, tetapi beliau menempatkan istrinya sebagai mitra hidup, yang kedudukannya sejajar dengan beliau, ada yang mendominasi atau terdominasi. Struktur keluarga inilah yang membentuk pola pikir Intan terhadap masalah peran dan kedudukan wanita dalam rumah tangga. Sehingga Intan bisa menentang dan menolak praktik kekerasan karena telah terkonsep dalam pikirannya bahwa wanita dan pria itu sejajar dan seharusnya ada sikap saling menghormati di antara kedua belah pihak sehingga akan tercipta hidup yang harmonis.

\footnotetext{
"Wong lanang sing gelem maratangan utawa mulasara sing wadon dudu priya sing jantan, ora sembada karo olehe dadi lanang sing kudune ngayomi wanita kang ringkih
} 
nanging dheweke kosok baline." Ukara kuwi tau diucapake dening bapake nalika diwaduli dening Bulik Surtini, adhine bapake lan sedulur siji-sijine. Kala semana Intan isih pacaran karo Pram. Bulik Surtini purik menyang omahe wong tuwane amarga mentas diajar dening sing lanang. Bapake nesu gedhe, mbelani adhine. Malah wektu semana bapake uga njumurungake supaya bulik Surtini njaluk pisah. Nanging bareng dilimbang-limbang, sidane bulik Surtini njaluk pisah. Nanging bareng dilimbang-limbang, sidane Bulik Surtini bali meneh menyang omahe dheweke sawise sing lanang njaluk ngapura. Urusan dianggep rampung! Nanging ing liya wektu pakulinan elek iku dibaleni maneh dening bojone. Sepisan iki bapake Intan minangka wakile wong tuwa, ora bisa aweh toleransi maneh

"Yen kowe saiki tetep ora gelem ngunggahake gugatan, mengko liya wektu si Karim bojomu kuwi bakal mulasara kowe maneh. Yen watuk ngono pancen bisa ditambani, nanging yen watak? Angel didandani! Apa kowe gelem tansah dadi korban terus selawase uripmu?" kandhane bapake maneh (Pangastuti, 2016: 53-54).

Terjemahan:

"Laki-laki yang suka memukul dan menganiaya istrinya bukan laki-laki yang jantan., seharusnya tugas laki-laki itu mengayomi perempuan, tetapi dia justru sebaliknya." kalimat ini pernah diutarakan oleh bapaknya ketika mendapat cerita dari bulik Surtini, adik dari bapaknya dan merupakan saudara satu-satunya. Ketika itu Intang berpacaran dengan Pram. Bulik Surtini kabur ke rumah orang tuanya setelah mendapat perlakuan kasar dari suaminya. Bapak marah besar dan membela adikknua. Bahkan waktu itu bapaknya juga menyarankan bulik Surtini untuk berpisah dari suaminya. Setelah dipertimbangkan, akhirnya bulik Surtini kembali ke rumahnya kembali setelah suaminya meminta maaf. Masalah dianggap selesai! Tetapi dilain waktu kebiasaan buruk suaminya terulang kembali. Pertama, bapaknya Intan sebagai wakil dari orang tua tidak bisa menerima lagi.

"Jika kamu tidak segera mengajukan gugatan, lain kesempatan si Karim suamimu itu akan menganiaya kamu lagi. Ibarat kalau batuk bisa disembuhkan, tetapi kalau watak?! sulit diubah. Apa kamu mau jadi korban terus sepanjang hidupmu? Tanya bapaknya.

Perkembangan kepribadian juga bisa dipengaruhi oleh sikap orang tua terhadap suatu permasalahan. Sikap Pak Surtana yang menolak segala wujud kekerasan dalam rumah tangga berpengaruh terhadap perkembangan pola pikir Intan terhadap kekerasan. Intan juga menunjukkan sikap menolak kekerasan yang dilakukan oleh lakilaki. Pola asuh, nasihat dan larangan menjadi faktor yang ikut menentukan pola pikir Intan khususnya berhubungan dengan peran dan kedudukan antara laki-laki dan perempuan di dalam masyarakat.

\section{Faktor Ketidaksadaran}

Faktor ketidaksadaran sangat berhubungan dengan pola asuh. Karena perkembangan faktor ketidaksadaran ini dipengaruhi juga oleh pola asuh yang diterapkan. menjelaskan bahwa the network of kinship and subsequently of work, that sexual difference in all its certainty and uncertainty is first constructed.

Perkembangan psikologis seseorang itu melalui dua proses yaitu primary process dan secondary process. Proses primer berhubungan dengan hal-hal yang berada di wilayah ketidaksadaran yaitu berupa aturanaturan atau norma-norma di masyarakat.

Intan pancen digedhekake jroning kulawarga priyayi sing santun. Wong tuwane klebu kinormat sing dieringi dening masyarakat sakiwatengene. Najan anak ontang-anting nanging ora ungunan. Kuwi amarga dhidhikan bapake sing dhisiplin lan panggulawenthah saka ibune sing kebak asih lan wicaksana. Kawit Intan isih cilik wis ditemenake rasa tepa selira ing jiwane. 
Pancen, ibune ora tau ngandhani kanthi langsung, nanging biasane lewat dongeng, liwat buku-buku apa dene tuladha saka ibune dhewe. Kepriye sikape ibune marang rewang ing ngomahe, marang tangga teparo lan uga marang sedulur-sedulure saka garis ibu apa dene bapak. Kabeh kuwi kerekam cetha ing engatene. Ah, mangsa-mangsa kang endah! Pengin rasane bisa bali dadi bocah maneh. Urip tanpa sanggan, batine Intan kelingan mangsa-mangsa endah sing saiki wis mungkur kuwi. (Pangastuti, 2016:25).

Terjemahan:

Intan dibesarkan dalam keluarga yang santun. Orang tuanya termasuk orang terhormat dan disegani oleh masyarakat. Walaupun anak tunggal tetapi dia tidak manja. Hal ini karena didikan dari ayahnya yang disiplin dan ibunya yang bijaksana serta penuh kasih. Dari kecil Intan sudah ditanamkan rasa empati dalam dirinya. Memang, ibunya tidak memberitahu hal ini secara langsung tetapi biasanya dengan cara mendongeng, buku atau tindakan ibunya yang bisa dilihat secara langsung oleh Intan. Bagimana sikap ibunya kepada pembantu dirumah, sikap ibunya kepada tetangga dan saudara. Semua terekam dalam ingatan Intan." Ah, masamasa yang indah! Ingin rasanya kembali ke masa kecil. Hidup tanpa beban". Batin Intan mengingat masa-masa yang lalu.

Juliet Mitchell fokus terhadap perkembangan individu melalui proses ketidaksadaran. Proses tersebut akan membangun pola pikir seseorang. Faktor ketidaksadaran berhungan dengan kepribadian. Seseorang yang memiliki dominansi unsur kepribadian superego akan cenderung berperilaku yang sesuai dengan moral. Dominansi superego pada seseorang bisa diperoleh dari ajaranajaran orang tua. Pola asuh dari orang tua Intan mengembangkan keribadian yang baik pada Intan. Hal ini juga berpengaruh terhadap kepribadian Intan yang tenang dalam mengambil setiap keputusan. Setiap keputusan yang diambil dipikir secara mendalam dan hati-hati. Intan akan mempertimbangkan baik dan buruknya resiko yang dihasilkan dari keputusannya tersebut.

Intan besar tanpa kekurangan kasih sayang dan perhatian dari orang tua. Intan juga dididik mandiri oleh kedua orang tuanya, hal ini berpengaruh terhadap kondisi psikologisnya. Intan memeliki kondisi psikologis yang stabil. Kestabilan psikologis tersebut dapat dilihat dari perilaku Intan menyelesaikan masalah di dalam rumah tangganya. Intan tampak tenang walaupun dia dalam posisi yang terancam. Semua pengalaman-pengalaman dan pola asuh yang didapatkan Intan ketika kecil menjadi bagian dari alam bawah sadarnya yang pada akhirnya berpengaruh terhadap setiap keputusan yang diambil.

\section{Simpulan}

Dari kajian di atas dapat disimpulkan bahwa, perilaku yang ditunjukkan oleh tokoh wanita dalam novel Alun Samudra Rasa yaitu Intan ada lima yaitu mengusir, menggugat cerai, kekerasan fisik, kekerasan psikologis dan mencintai laki-laki lain kecuali suaminya. Setiap perilaku dipikir secara mendalam dan hati-hati mengingat Intan masih memegang teguh etika dan prinsip sebagai wanita Jawa. Perilaku yang ditunjukkan oleh tokoh wanita jika dilihat dari pandangan psikologis merupakan ekspresi rasa cemas atau kecemasan yang dialaminya. Perilaku-peri-laku tersebut sebagai bagian dari upaya untuk mengurangi rasa kecemasan yang dirasakan.

Jika dikaji lebih mendalam dengan menggunakan teori Mitchell, ditemukan dua faktor yang menyebabkan wanita bisa melawan praktik kekerasan yang menimpanya yaitu faktor pola asuh dah faktor ketidaksadaran. Perbedaan pola asuh akan menyebabkan perbedaan pola pikir yang akhirnya akan berpengaruh juga terhadap perbedaan cara pandang terhadap suatu hal khususnya masalah sexual difference. Pola asuh yang masih kental dengan nuansa Jawa menjadikan perilaku sebagai reaksi dari 
adanya kekerasan juga masih dalam batas norma Jawa. Wanita Jawa.

Saran bagi peneliti selanjutnya, novel Alun Samudra Rasa bisa dijadikan bahan penelitian selanjutnya. Banyak aspek dalam novel ini yang masih bisa diangkat sebagai karya ilmiah. Peneliti lain bisa mengkaji novel ini dari aspek sosiologi sastra.

\section{Daftar Pustaka}

Duschinsky, Robby \& Susan Walker. 2015. Juliet Mitchell and The Lateral Axis: Twenty First Century Psychoanalysis and Feminis. New York: Palgrave Macmillan.

https://doi.org/10.1057/9781137367792

Endraswara, Suwardi .2011. Metodologi Penelitian Sastra. Yogyakarta: Media Press.

Irianingsih, Endang Tri. 2016. “Menggugah Kesadaran Perempuan dengan Islam dan Tradisi Jawa" dalam prosiding Konferensi Internasional Feminisme: Persilangan Identitas, Agensi dan Politik. Jakarta. Yayasan Jurnal Perempuan.

Ismiyati, Siti Ajar. 2011. “Feminisme Dalam Kumpulan Cerpen Harga Perempuan Karya Sirikit Syah" dalam Jurnal Widyaparwa Volume 39, Nomor 2, Desember 2011. doi: 10.26499/wdprw.v39i2.37

Minderop, Albertine. 2011. Psikologi Sastra : Karya Sastra, Metode, Teori, dan Contoh Kasus. Jakarta: Pustaka Obor Indonesia.

Mitchell, Juliet. 2000. Psychoanalysis and Feminism: a Radical Reassesment of Freudian Psychoanalysis. New York: Basic Books.

Ogene, Mbanefo, S., 2013. "Psychoanalysis and Study of DH Lawrence's Son and Lovers." Int. J. Lang. Lit. Gend. Stud. 2, 95-116. https://doi.org/https://www.ajol.info/index .php/laligens/article/view/108005/97837

Ratna, Nyoman Kutha. 2015. Teori Metode dan Teknik Penelitian Sastra. Yogyakarta: Pustaka Pelajar.

Siswantoro. 2005. Metode Penelitian sastra : Analisis Psikologis. Malang: Muhammadiyah University Press.

Sugihastuti \& Itsna Hadi Saptiawan . 2010. Gender $\mathcal{E}$ Inferioritas Perempuan: Praktik Kritik Sastra Feminis. Yogyakarta: Pustaka Pelajar.

2010. Kritis Sastra Feminis: Teori dan Aplikasinya. Yogyakarta: Pustaka Pelajar.

Sumodiningrat, Gunawan dan Ari Wulandari. 2014. Pitutur Luhur Budaya Jawa. Yogyakarta: Narasi

Suseno, Franz Magnis. 1985. Etika Jawa.Jakarta: PT Gramedia.

Tong, Rosemary Putnam. 2006. Feminist Thought A More Comprehensive Introduction. Diterjemahkan dalam Bahasa Indonesia oleh QuainiPriyatna Prabasmara. Bandung: Jalasutra

Vidiyanti, M.O., 2014. Biner pada tokoh perawan sunthi. Widyaparwa 42, 89-96. doi: 10.26499/wdprw.v39i2.37

Wiyatmi.2012. Kritik Sastra Feminis: Teori dan Aplikasinya dalam Sastra Indonesia. Yogyakarta: Penerbit Ombak.

2013. Menjadi Perempuan Terdidik: Novel Indonesia dan Feminisme. Yogyakarta: UNY Press 